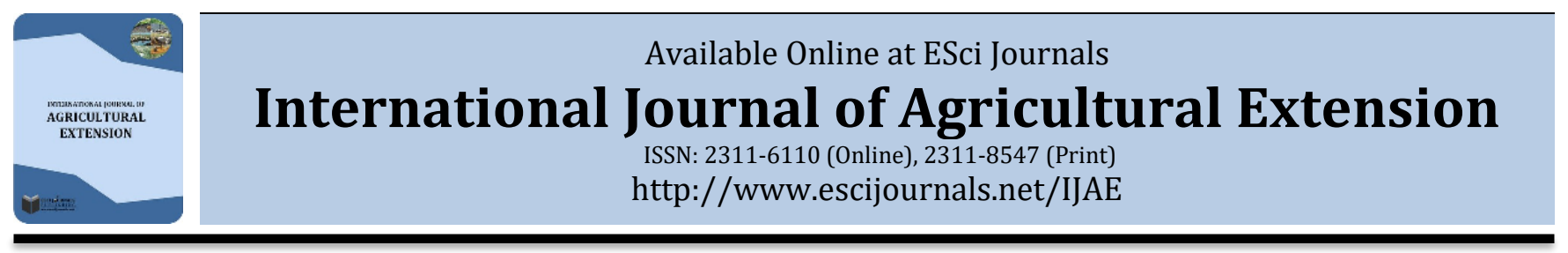

\title{
FARMERS INVOLVEMENT IN FARMER-BASED ORGANIZATION AND PERCEIVED CHALLENGES: A CASE OF OSHIKOTO REGION, NAMIBIA
}

\author{
aCecilie N. Jona*, bMargareth N. Nghixulifwa \\ a University of Namibia (UNAM) Neudamm campus, Windhoek Namibia. \\ ${ }^{b}$ University of Namibia (UNAM) Oshakati campus, Namibia.
}

\section{A B S T R A C T}

Farmer-based organisations (FBOs) are formed in the communal farming communities, mostly by Agricultural Support Services (ASS) providers with the aim that rural communities will become sustainable and manage their own community development activities. However, too often these FBOs do not receive sufficient support and training from the ASS providers and do not advance from being mere participants to being self-reliant as organisations so that they can make their own decisions as a group. This paper will analyse farmer participation and involvement in FBOs and the challenges faced by FBOs. Using a random sampling technique, data were collected from 150 farmers from six constituencies in the Oshikoto region. The findings showed that only 65 out of 150 respondents belonged to an FBO. There were slightly more female respondents (52.3\%) than male respondents (47.7\%). Most FBO respondents participated at the constituency level (64.6\%), while $44.6 \%$ participated at the village level. Only $12.3 \%$ participated at the regional level, while none participated at the national level. Eighty per cent (80\%) of the respondents indicated that their main objective for joining the FBO was to obtain technical skills. However, $83.1 \%$ of the FBOs experienced the problem of members not attending meetings and $78.5 \%$ indicated that members do not pay registration fees and annual fees. The researcher concluded that the FBOs in the Oshikoto region need continuous training in various courses such as group dynamics, communication skills, and soft skills to run their FBOs successfully.

Keywords: Farmer participation, Farmer Base Organisation, challenges.

\section{INTRODUCTION}

In Namibia, the agricultural sector and related industries contribute $3.7 \%$ to the gross domestic product (GDP) of the country. The sector was also reported to be the largest employer in 2012 as it employed 172530 people, which represented $27.4 \%$ of the total employment in Namibia (Namibia Agriculture Policy, 2015). While the poverty level in the country seems to have reduced, it still remains high when compared to other countries' level of income per person (World Bank, 2017). According to the World Bank (2017), the international poverty line in 2015 was at $42.8 \%$ at $\$ 3.10$ a day, while in Namibia $16.9 \%$ of the population earned less than $\$ 1.90$ a day. In Namibia, the majority of the poor are women, subsistence farmers, and pensioners (Namibia Statistics Agency (NSA), 2012). Although the Ministry of

* Corresponding Author:

Email: cnjona@unam.na

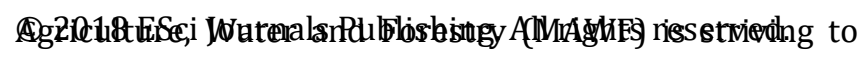

improve the living conditions of the farmers, much still needs to be done in the subsistence community sector. According to the Ministry of Agriculture, Water and Rural Development (MAWRD, 2003), the ratio of agricultural extension workers to farming households in the Oshikoto region was estimated at 1:1869 in 2003 and in 2016 this ratio slightly decreased to 1:1783 (Jona, 2016).

According to the Namibian Agricultural Policy (2015:24), Agricultural Extension Services' specific objectives, among others, are "to provide agricultural extension services in the form of communication, advisory and training to producers; and to facilitate a public-private partnership in extension services". The policy statements also mention the objective "to coordinate efforts of stakeholders in the design and delivery of extension services and to continue capacitating farmers' unions and associations".

The policy support capacitates farmers' groups and 
associations. As farmers' participation and involvement are very crucial for community development, no amount of investment, improved technology, or input supply will bring about a permanent improvement in the farmers' living standards (Boas \& Goldey, 2011). Farmers' empowerment can only be realised if they take control and participate in their own development activities (Fraser \& Villet, 1994; Boas \& Goldey, 2011). Chamala \& Shingi (2005:2) stated, "Telling adults what to do provokes a reaction, but showing them triggers the imagination, involving them gives understanding, and empowering them leads to commitment and action."

Participation in development can only be a reality if farmers are organised in groups or associations, which is an important element in the implementation of agricultural programmes, as well as the improvement of activities (Food and Agricultural Organization (FAO), 2000; Fraser \& Villet, 1994; Boas \& Goldey, 2011; Garforth \& Munro, 1995). Debrah \& Nederlof (2002) argued that farmers can only be empowered if they have an organisation that represents them on local, district, regional, and global levels. Debrah \& Nederlof (2002) further mentioned that organisations are good sources of information as they transmit information from farmers to the government, research and development and financial institutions, and vice versa. Garforth \& Munro (1995) were also of the opinion that it is easier and more efficient to work with a group than with individuals because members of an organisation are known to achieve the aims they would not have achieved on their own. Debrah \& Nederlof (2002) reported that in sub-Saharan Africa, all groups in the community, in the form of associations, cooperatives, or farmer-controlled companies, are part of FBOs. In this study, FBOs refer to groups, associations, and cooperatives.

Problem statement: The farmers in the Oshikoto region seem to have realised the importance of joining an association, cooperative, and/or FBO and, as such, organisations play an important role in negotiating with service providers, as well as in evaluating services received. It is also common knowledge that the voice of these groups would be better heard by the central government than an individual voice. The opposite is also true - weak farmers' organisations will be taken advantage of by other sectors and society by telling them what to do as well as speaking on their behalf (Pertev, 1994). Due to the high farmers-to-extension ratio in the Oshikoto region, FBOs can also provide extension services to farmers, as well as organising the purchase of inputs and the sale of products. However, most of the farmers' organisations seem to experience different challenges as they appear to be more dependent on the government than being self-sustaining, with clear objectives of what to achieve. Although the Agricultural Policy (2015) states that farmers' unions and associations need to be capacitated, the organisations still need be guided in order to strengthen their human capacity for sustainable development to be realised. This paper therefore attempted to analyse farmers' involvement in FBOs and the challenges encountered by the FBOs.

The study aimed to;

- assess gender and age and the different types of FBOs in the study area;

- assess the different levels of participation of the farmers in the FBOs;

- analyse the motives of joining FBOs and the challenges experienced in these groups; and

- understand the effectiveness and efficiency of working in groups.

\section{MATERIAL AND METHODS}

Description of the study area: For reasons of budgetary constraints and accessibility, the Oshikoto region was chosen for this study. The Oshikoto region is one of 13 regions in Namibia (see Figure 1). The region consists of $38653 \mathrm{~km}^{2}$ (3865300 ha) of land, of which $70 \%$ is utilised for agricultural practices (Ministry of Agriculture, Water and Rural Development (MAWRD), 2003b). Oshikoto is located in the northern part of the country and it is divided into two land tenure regimes. One part of the region consists of large-scale commercial farming units under free-hold title, and the other is dominantly communal land. Oshikoto consists of ten constituencies: Tsumeb, Guinas (predominantly commercial farmers), Omuthiyagwiipundi, Eengodi, Okankolo, Omuntele, Onyaanya, Onayena, Oniipa, and Olukonda (communal area). The municipal area is in Omuthiyagwiipundi and serves as the regional capital.

Research design: The survey research design was used in this study where questionnaires were administered randomly to 150 farmers drawn from, communal. According to Harwell (2011), qualitative research focuses on understanding the experiences as well as the thoughts of the participants as the results provide detailed, in-depth information.

Population and Sample: The populations of importance 
to this study were active farmers in the Oshikoto region. Communal farming includes all the households in the community who practise farming with the primary aim of feeding their families and to sell the surplus. It has been observed that the type of farming strongly influences the decisions that the farmers have to make, such as types of livestock to keep, crops to grow, FBOs to belong to, types of equipment to buy, and the market(s) to sell their agricultural produce to. From the ten

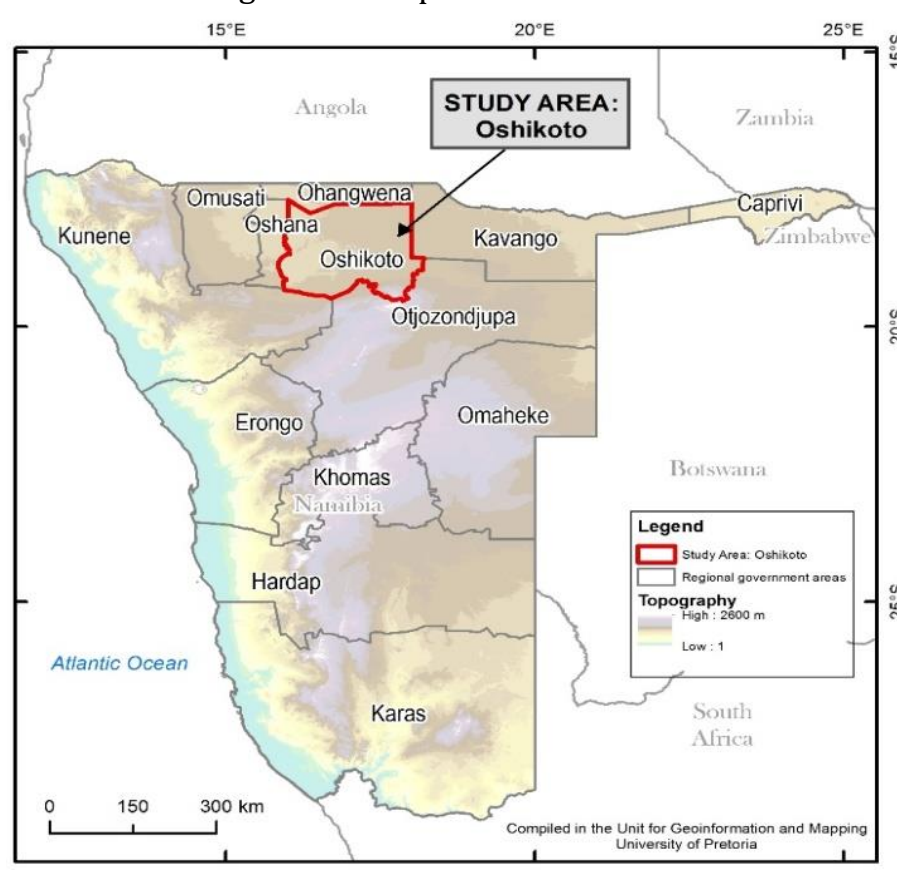

Figure 1. Map of the Oshikoto region.

Data collection and instrument: The study makes use of the qualitative method. Preliminary field visits to the study area were first conducted, which involved contacting local leaders to explain the purpose of the study. Some organisations in the region, such as the DEES, introduced the researcher to the different councillors. Some councillors took it upon themselves to review the research on radio and explain to the community that the research would be taking place and encouraged community members to fully participate in the study since the councillors approved the study. The pilot interviews were conducted at the DEES and on nearby farms in the area of Onakali, which is the main office of the DEES.

The questionnaires were improved according to the recommendations of the DEES staff members and the farmers' input. The data collection for this study consisted of quantitative pre-coded, close-ended questions and qualitative, open-ended questions. The constituency in the Oshikoto region eight constituencies mostly practise communal farming and is where $85 \%$ of the farming household are found (Population Census, 2011). Because the population in the communal settings is homogenous, the researcher randomly selected six constituencies, which were Omuntele, Onyaanya, Onayena, Oniipa, Olukonda, and Oniipa, from the communal area, and $(\mathrm{n}=150)$.

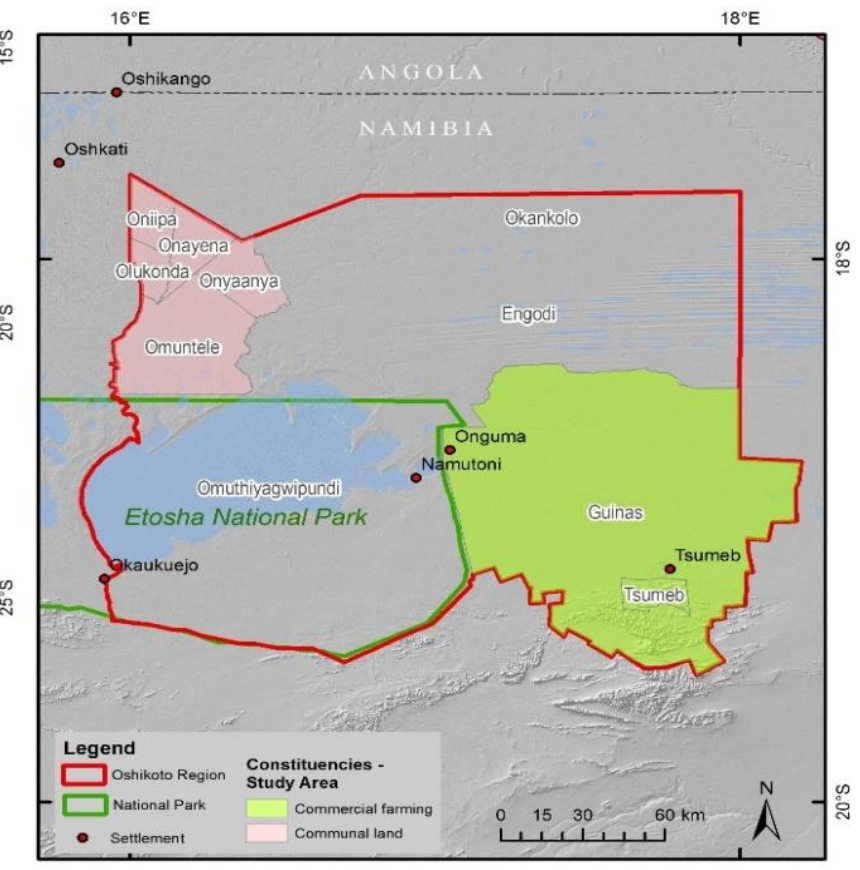

data-collection tools focused on all the issues reflected in the research objectives.

Six research assistants were employed in each of the following constituencies: Omuntele, Onyaanya, Onayena, Oniipa, Olukonda, Oniipa. Ten farmers were chosen for further pilot testing of the questionnaire, which was administered to assist in the content and validity verification of the instrument. To ensure that the study went smoothly, it was important that all the research assistants employed could communicate in the vernacular language. The researcher provided these fieldworkers with background information on the study and trained them in the administration of the questionnaires.

The objectives of the study were explained to the research assistance and the training took place in the local language. Comments on the questionnaire were taken into consideration for the perfection of the questionnaire; unclear questions were removed, and 
some questions were amended. While the administration of the questionnaires was in progress in the constituencies, the researcher rotated to supervise the research assistants and to answer any questions that they might have.

Data Analysis: Before the analysis of the data, the responses were checked with the aid of the relevant interviewer to ensure consistency and completeness. The responses to the questions were numerically coded, captured on computer, and then analysed using SAS statistical software.

The data analysis included descriptive statistics that described and summarised the data, and appropriate inferential statistics to compare the groups, for example according to gender and age. The comparison of the different groups was performed by using tables, as well as testing significance differences with the chi-square test. Means and standard deviations of different frequencies and ranking of different organisations were also performed. The qualitative data analysis was conducted manually by reviewing the notes and transcripts to identify appropriate themes. The data extracted from the relevant documents were also presented in tables and discussed in the context of the research objectives.

Validity and reliability: Rigour is an indispensable component of all research in general and of case study research in particular (Miles \& Huberman, 1994; Yin, 2003). Therefore, the researcher complied with wellestablished criteria and logical assessment during the research process to ensure the quality of the research and credibility for the scientific community. In addition, content validity was addressed by ensuring that the data-collection instruments (both the questionnaire and the interview schedule) were designed very carefully to include all the necessary questions related to the research objectives. All the principles of constructing a questionnaire, including avoiding leading questions and ambiguous or vague questions, not using a very long questionnaire, putting together similar questions in sections or sub-sections, not including sensitive questions at the beginning of the questionnaire, were strictly followed. The study also employed a variety of qualitative techniques to gather data, such as in-depth interviews, focus groups, a semi-structured questionnaire, and observations to explore the views and opinions of the sample respondents. The qualitative data were also validated by following the logic in which the questions were checked and rechecked against the objectives of the study and for their relevance to the study's overall objective. Pre-testing or piloting of the data-collection instruments was performed to increase their validity.

Ethical Issues: Aspects that relate to ethical behaviour for this study include the following;

- Confidentiality and anonymity in terms of which all the participants were informed of the confidentiality and anonymity of the study before completing the questionnaires. The respondents were also informed that their participation in the study is voluntary and under no circumstance should they feel either forced or obliged to complete the questionnaire.

- All the respondents were informed from the beginning that there would not be any incentives, or any financial rewards offered to them.

\section{RESULTS AND DISCUSSION}

Demographic attributes of the respondents: Table 1 shows that there were slightly more female respondents (34 respondents, or $52.3 \%$ ) than male respondents (31 respondents, or $47.7 \%$ ) who participated in FBOs. The younger participants, of the age category 21-40, who participated in the groups represented only $18.5 \%$ (12 respondents). Debrah \& Nederlof (2002) reported that younger farmers do not feel comfortable expressing their views in the company of their elders in a traditional setup. Groverman et al. (1995) reported that women were reluctant to express their views or challenge the views of male participants in public. According to respondents in the age category 41-60, more females (50\%) than males (45.2\%) participated in FBOs, while only $33.8 \%$ of the participants above the age of 61 participated in FBOs.

Table1. Percentage distribution of respondents by age and gender who belong to an FBO.

\begin{tabular}{|c|c|c|c|c|c|c|}
\hline \multirow{2}{*}{ Age } & \multicolumn{2}{|c|}{ Male $(n=31) 47.7 \%$} & \multicolumn{2}{|c|}{ Female $(n=34) 52.3 \%$} & \multicolumn{2}{|c|}{ Total (65) } \\
\hline & $\mathrm{f}$ & $\%$ & $f$ & $\%$ & $f$ & $\%$ \\
\hline $21-40$ & 6 & 19.36 & 6 & 17.65 & 12 & 18.5 \\
\hline $41-60$ & 14 & 45.16 & 17 & 50 & 31 & 47.7 \\
\hline Above 61 & 11 & 35.48 & 11 & 32.35 & 22 & 33.8 \\
\hline Total & 31 & 100 & 34 & 100 & 65 & 100 \\
\hline
\end{tabular}


Respondents in the Oshikoto region were asked to state to which type of FBO they belong. Table 2 presents the percentage of farmers who belong to a cooperative, farmers' association, or community project. Only $32.5 \%$ (or 65) of the respondents out of 150 farmers interviewed belonged to FBOs in communal farmer settings. Groverman et al. (1995) urged that to avoid conflict within a group, such a group should consist of homogenous members who share the same socioeconomic conditions. According to Table 2, of the farmers, $32.3 \%$ respondents belonged to a cooperative, $43.1 \%$ (28 respondents) to a farmers' association, and $24.6 \%$ (16 respondents) to community projects.

Level of participation: Figure 1 presents the responses of the farmers who were asked to state at what level they participate in FBOs.

Table 2. Percentage of farmers per type of FBO membership in the Oshikoto region.

\begin{tabular}{lcc}
\hline Type of organisation & $\mathrm{n}$ & $\%$ \\
\hline Farmers' associations & 28 & 43.1 \\
Cooperatives & 21 & 32.3 \\
Community projects & 16 & 24.6 \\
Total & 65 & 100 \\
\hline
\end{tabular}

Source: Generated from survey data.

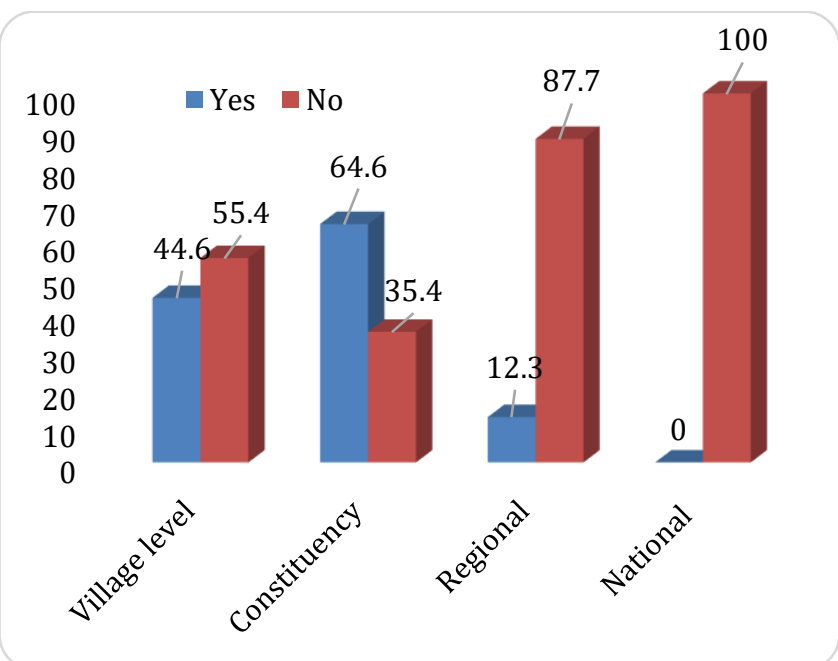

Figure 2. Respondents' participation in FBOs according to different levels.

According to Figure 2, the majority of the farmers (64.6\%) participated in FBOs at the constituency level and $44.6 \%$ at the village level. Only $12.3 \%$ of the farmers participated at the regional level, and none participated at the national level. Debrah \& Nederlof (2002) reported that a lack of proper consultation at village level leads to farmers not being represented properly in the hierarchical organisational structure, resulting in a few farmers speaking on behalf of most of the farmers. The latter is evident in Figure 1, with no representation at the national level. Debrah \& Nederlof (2002) further argued that a lack of representatives at the top-level structure leads to a lack of influence in agricultural policies. For proper flow of information, FBOs need to be properly represented at all the hierarchical levels.

Motive for joining FBOs: The farmers were asked to state their motive(s) for joining an FBO. Figure 3 indicates the farmers' responses.

According to Figure $3,80 \%$ of the farmers indicated that their main objective for joining an FBO was to obtain technical skills that were provided by the FBO. Boas and Goldey (2011) stated that FBOs that cannot provide technical advice face sustainability problems. This finding was supported by Debrah \& Nederlof (2002), the Neuchâtel Group (2007), \& Korten (1980); all of whom were of the opinion that genuine and effective FBOs should provide services to their group members. If need be, the FBO must contract private expertise to deliver the services on its behalf. Well-organised FBOs can influence policy decisions and negotiate input prices on their members' behalf (Korten, 1980).

The second objective was to improve the marketing of agricultural produce (69.2\%). The third objective was to obtain bargaining power for farmers (40\%). Lyon (2003) found that when farmers negotiate their prices, it empowers them to have greater control over commodity prices. Lyon (2003) also confirmed that bargaining for prices works best when farmers do not owe credit to traders - otherwise they would dictate prices for the farmers. Of the members, $36.9 \%$ joined an FBO because it acts as a voice for the members. Only $33.8 \%$ of the members joined the group to be provided with legal support.

Problems experienced by farmers in FBOs: The farmers were asked to state their views on the different problems they experienced in their FBOs. Their responses are illustrated in Figure 4.

According to Figure 4, 83.1\% of the FBO members experienced the problem of members not attending meetings. Groverman et al. (1995) emphasised that group meetings are the ideal place for discussions, learning, and decisions to take place. Of the farmers, $78.5 \%$ indicated problems such as members not paying registration fees and annual fees. 


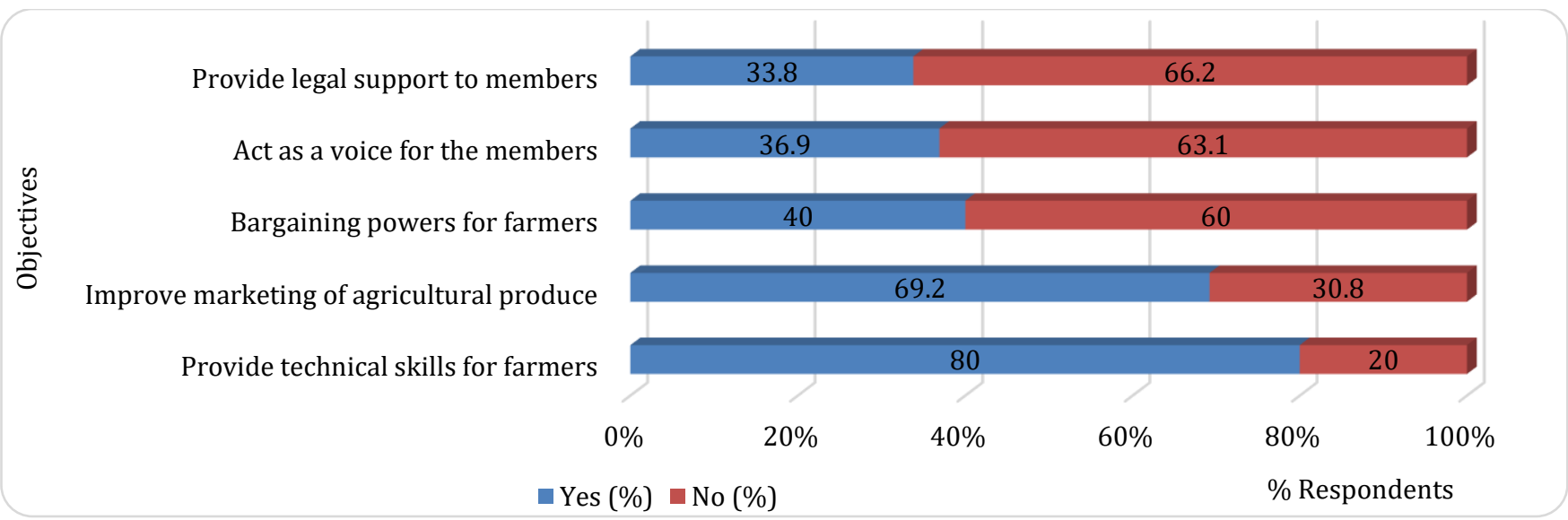

Figure 3. Percentage distribution of problems experienced by farmers in their FBOs.

Source: Generated from survey data.

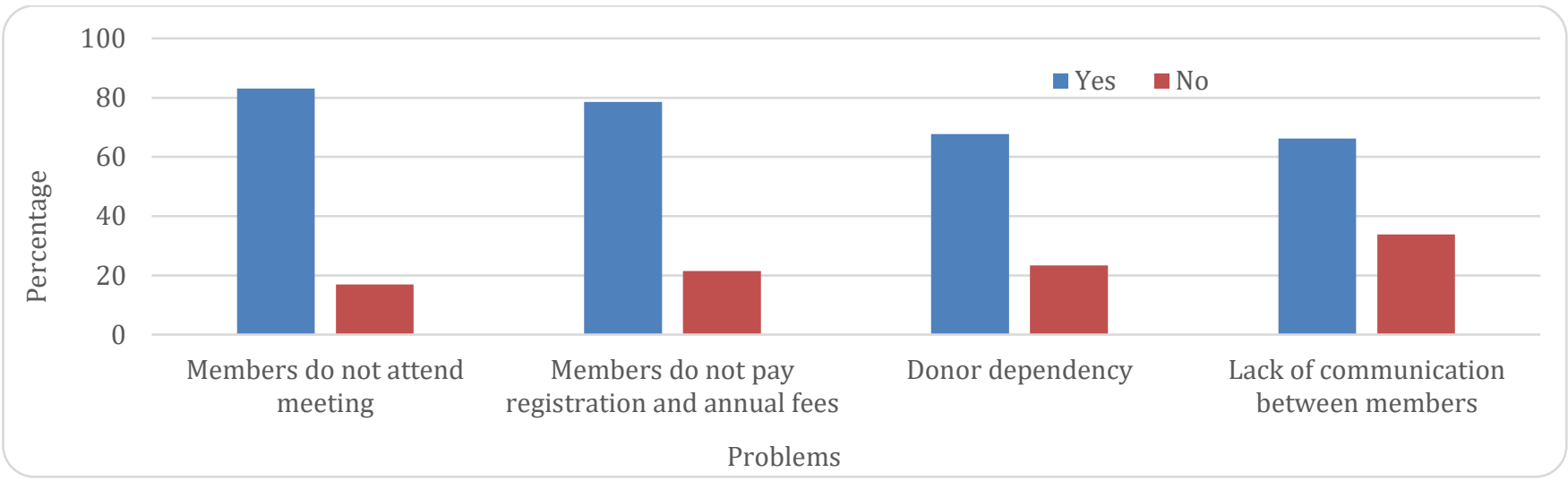

Figure 4. Percentage distribution of problems experienced by farmers in their FBOs.

According to the Neuchâtel Group (2007), paying membership fees increases accountability and members' commitment. Groverman et al. (1995) stated that membership fees encourage group unity and also pay for smaller expenses such as stationery, transport, etc. Boas \& Goldey (2011) noted that some farmers participate in FBOs hoping that they would obtain economic benefits such as tractor services, transport for products, and better commodity prices. Donor dependency was the third problem, mentioned by $67.7 \%$ of the respondents. Boas \& Goldey (2011), Debrah \& Nederlof (2002), and Bingen, Serrano and Howard (2003) stated that FBOs created by external bodies without real commitment are bound to fail when outsiders withdraw. Lastly, $66.2 \%$ of the farmers indicated a lack of communication between group members as a problem. Communication is a twoway stream that strengthens relations between group members and guides the group in the right direction (Fraser \& Villet, 1994; Groverman et al., 1995). Poor communication creates misunderstandings and irritation, which might lead to the failure of the group. Effectiveness and efficiency of FBOs: The respondents were asked to state whether or not their groups were effective and efficient. Figure 5 indicates group members' perceptions of the effectiveness and efficiency of their FBOs.

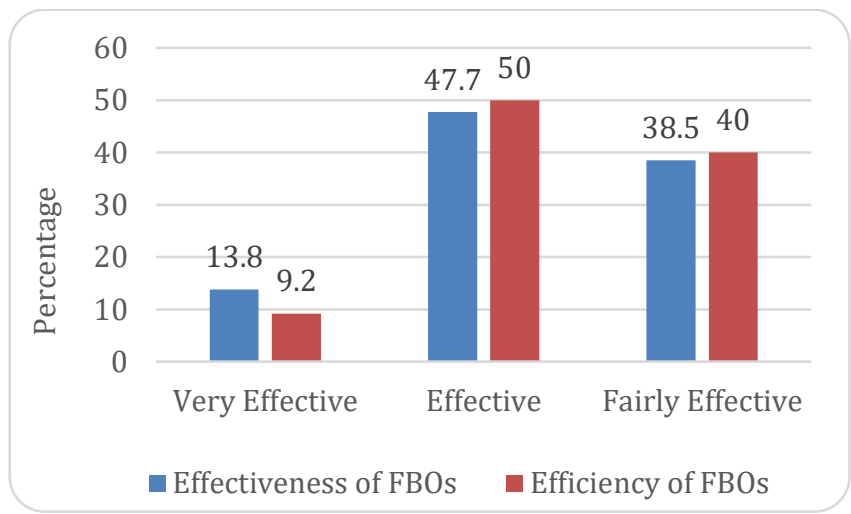

Figure 5. Respondents' views on the effectiveness and efficiency of their FBOs. 
As evident in Figure 5, the respondents perceived their groups as effective (47.7\%) and efficient (50\%). Only small percentages of $13.8 \%$ and $9.2 \%$ were of the opinion that the groups were very efficient and very effective respectively.

Although these are small percentages, they are a cause for concern because one can only stay loyal to a group if it is rewarding. Forty per cent (40\%) of the farmers perceived their groups as fairly effective, and 38.5\% perceived their groups as fairly efficient. The possible reason could be that the respondents benefited from belonging to a group, but the FBOs need to be strengthened to move from efficient to very efficient and from effective to very effective.

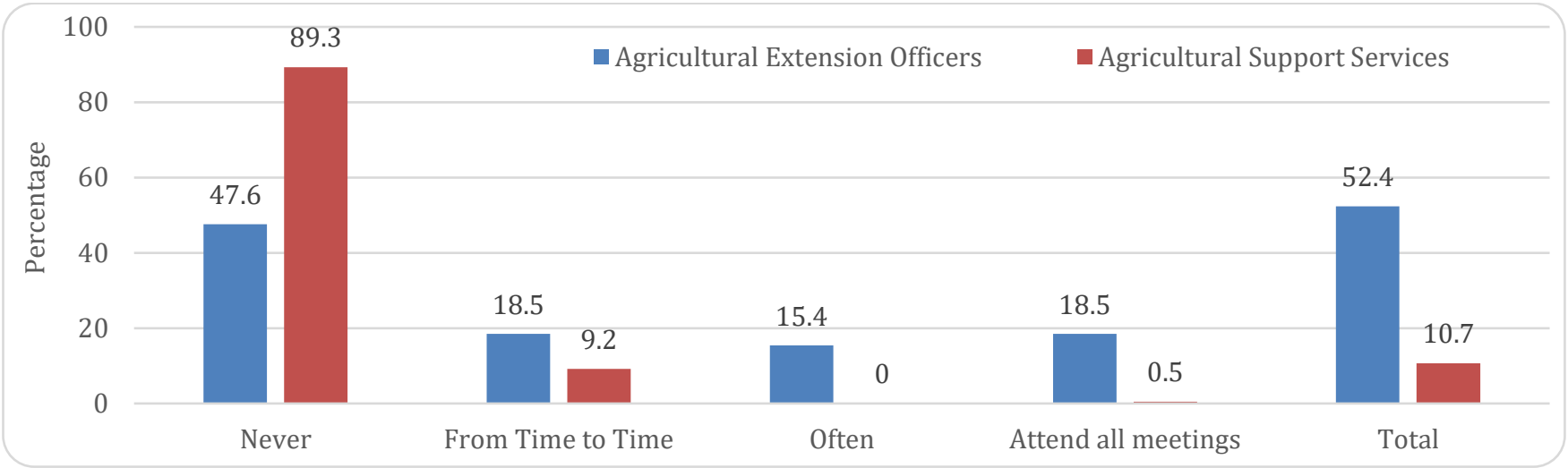

Figure 5. Respondents' responses on how often extension officers and ASS attend their meetings.

Attendance of meetings by extension officers and other ASS providers: Figure 5 indicates the responses to the question where respondents were asked to indicate how often agricultural extension officers and other ASS providers attend their meetings

According to Figure 5, 52.4\% (or 34) of the respondents reported that extension officers attended their meetings, and only $10.7 \%$ (or seven) of the respondents indicated that ASS providers attended their meetings. It is evident that the views of the farmers were divided as $18.5 \%$ (or six) of the respondents mentioned that agricultural extension officers attended all their meetings, while others stated that the attendance was from time to time. This finding corresponds with Boas \& Goldey (2011) that an FBO advised by extension officers is better equipped to sustain the organisation. It is evident from the results that the extension officers made more effort to attend the meetings, compared to the ASS providers who never attended meetings - according to $89.3 \%$ (or 58 ) of the respondents. All the ASS providers in the region need to be advised to work together as a group to improve the living conditions of the farmers for Vision 2030 to be accomplished.

According to Table 3, 49.2\% (or 32) of the respondents indicated that FBOs had made some effort to keep the group together, and 40\% (26 respondents) indicated that FBOs had made considerable effort to maintain the group. Only $9.2 \%$ (six respondents) indicated that minimal effort was made to keep the group together. It is, however, important that the group members advance from some effort to considerable effort in maintaining the groups.

Table 3. Perceptions of respondents of the effort made in maintaining the group.

\begin{tabular}{lccc}
\hline Effort & Frequency & $\%$ & Cumulative \% \\
\hline No effort at all & 1 & 1.5 & 1.5 \\
Very little effort & 6 & 9.2 & 10.8 \\
$\begin{array}{l}\text { Some effort } \\
\text { Considerable }\end{array}$ & 32 & 49.2 & 60.0 \\
effort & 26 & 40.0 & 100 \\
\hline Total & 65 & 100 & - \\
\hline
\end{tabular}

\section{CONCLUSION AND RECOMMENDATIONS}

Only a few farmers $(32.5 \%)$ participated in FBOs in the Oshikoto region. Farmers need to be encouraged to join FBOs in the region as there are many advantages such as training and marketing of produce; farmers who work individually do not have these advantages. The FBOs should be needs driven, i.e. farmers should identify and rank their needs according to importance with the assistance of ASS providers but without the influence of the ASS providers. It should also be encouraged that farmers join the groups for reasons that will benefit the group. It is important that awareness is aggressively 
created at the beginning and that farmers understand the objectives of their FBO.

The results indicate that only a few of the ASS providers attended FBO meetings. The group members need support from ASS providers in managing their own FBO. ASS providers can thus encourage and remind the FBO continuously of the objectives and achievements until the FBO progresses from passive participation to selfreliance and have ownership of their FBO to manage their organisation independently. The FBO members should feel that they own the group projects by making their own decisions without outside influence. It is evident from the results that the FBO members in the Oshikoto region need much support from the extension officers and the ASS providers to function effectively and efficiently in order to sustain themselves. It is of paramount importance that the FBO leaders undergo continuous training in different courses such as communication skills, group dynamics, soft skills, bookkeeping, and entrepreneurship to be able to run their groups effectively.

The leadership structures of the FBOs seem weak and need to be strengthened to lead to sustainable and financially stable organisations. The groups were faced with many problems that need to be solved, including dependency on donor funding and members not paying their contributions as they are supposed to. It is only when an FBO is active and functional that the income level can be increased and the standard of living in the rural areas can be improved.

\section{REFERENCES}

Bingen, J., Serrano, A. \& Howard, J. (2003). Linking farmers to markets: Different approaches to human capital development. Food Policy, 28(4), 405-419.

Boas, A.A.V. \& Goldey, P. (2011). A comparison of farmers' participation in farmers' organisations and implications for rural extension in minas gears. Organizações Rurais \& Agroindustriais, $7(3), 259-270$.

Chamala, S. \& Shingi, P.M. (2005). Establishing and strengthening farmer organizations. In Improving agricultural extension: A reference manual, edited by B. Swanson. Rome: FAO. p. 193.

Debrah, S.K. \& Nederlof, E.S. (2002). Empowering farmers for effective participation in decision making. USA: International Center for Soil Fertility and Agricultural Development (IFDC).
Food and Agriculture Organization (FAO). (2000). Virtual Extension, Research and Communication Network (VERCON). Rome: FAO.

Fraser, C. \& Villet, J. (1994). Communication: A key to human development. Rome: FAO.

Garforth, C. \& Munro, M. (1995). Rural people's organisations and agricultural development in the upper north of Thailand: Phase 1 of a joint research project. Reading: Agricultural Extension and Rural Development Department, University of Reading.

Groverman, V., Cook, J. \& Thomas, G. (1995). The group promoter's resource book: A practical guide to building rural self-help groups. Rome: FAO.

Harwell, M.R. (2011). Research design in qualitative/quantitative/mixed methods: The Sage handbook for research in education (2nd ed). Los Angeles, CA: Sage Publications.

Jona, C.N. (2016). Developing a framework for improving coordination in the provision of agricultural support services to farmers in the Oshikoto region in Namibia. PhD thesis, University of Pretoria, Pretoria, South Africa.

Korten, D.C. (1980). Community organization and rural development: A learning process approach. Public Administration Review, 40(5), 480-511.

Lyon, F. (2003). Community groups and livelihoods in remote rural areas of Ghana: How small-scale farmers sustain collective action. Community Development Journal, 38(4), 323-331.

Miles, M.B. \& Huberman A.M. (1994). Qualitative Data Analysis (2nd ed). London: Sage Publications

Ministry of Agriculture, Water and Rural Development (MAWRD). (2003). Baseline survey of impact of Agricultural Extension Services in Oshikoto region. Tsumeb, Namibia: MAWRD.

Ministry of Agriculture, Water and Forestry (MAWF). (2015). Namibia Agricultural Policy 2015. Windhoek, Republic of Namibia.

Namibia Statistics Agency (NSA). (2012). Poverty dynamics in Namibia: A comparative study using the 1993/94, 2003/04 and the 2009/10 NHIES survey. Windhoek, Namibia: NSA.

Namibia Statistics Agency (NSA). (2014). Namibia Census of Agriculture 2013/2014: Communal sector. Windhoek, Namibia: NPC.

Neuchâtel Group. (2007). Demand driven advisory services. Lindau, Switzerland: Swiss Centre for 
Int. J. Agr. Ext. 06 (02) 2018. 61-69

Agricultural Extension and Rural Development (AGRIDEA).

Pertev, R. (2014). The role of farmers and farmers' organizations. Cashiers Options, Méditerranéennes, 2(4), 27-31.
World Bank. (2017). Does fiscal policy benefit the poor and reduce inequality in Namibia? Washington, D.C.: Internal Bank for Reconstruction and Development / World Bank. 